\title{
Family Intimacy and Social Support Mediate the Relationship between National Identity and Cultural Alienation among Adolescents of Li Nationality
}

\author{
Shengwei Ning and Huirong Cao \\ School of Education, Hainan Tropical Ocean University, Hainan Sanya, China
}

\begin{abstract}
In order to promote adolescents of Li's national identity and acculturation, we use the questionnaires which are the national identity questionnaire, the cultural alienation of ethnic students, family intimacy and adaptability questionnaire, social support questionnaire to investigate $1008 \mathrm{Li}$ adolescents in Hainan. This paper established a structural equation model, and explored that the national identity of $\mathrm{Li}$ adolescents has direct negative effect to the cultural alienation. The total effect $c$ was -0.261 , the direct effect was significant $\left(c^{\prime}=-0.208, p<0.001\right)$, the total indirect effect was significant too $\left(c-c^{\prime}=-0.053, p<0.001\right)$. The adolescents of Li's national identity can indirectly influence cultural alienation through family intimacy $\left(a_{1} b_{1}=-0.032\right.$, $p<0.010$ ), also indirectly influence cultural alienation by social support $\left(a_{2} b_{2}=-0.021, p<0.01\right)$. The family intimacy and social support play multiple mediating roles in Li adolescents' national identity and cultural alienation.
\end{abstract}

Keyword-national identity; cultural alienation; social support; family intimacy; multiple mediation effects

\section{INTRODUCTION}

Cultural alienation is a kind of negative emotion in the cross cultural background which is due to cultural difference to produce the sense of the separation, isolation, being accused, disharmony and the sense of non-involvement of the mother culture and the mainstream culture [1]. The Li nationality, more than 1.2 million, is living in Hainan Province. As the southernmost minority in China, due to historical reasons and the unique geographical location, it forms a unique island culture. In the background of international tourism island develop the ethnic cultural tourism and during the minority traditional culture interact and impact the mainstream culture and foreign culture. It is continual to conflict and integration the "local tradition" and "modern development". Li adolescents exists cultural difference in the blend and coexistence of traditional cultural, mainstream cultural and foreign cultural and cause the sense of cultural alienation. Cultural alienation is a form of psychological alienation, and is also a major indicator of mental health [2]. In this paper, we research that the sense of adolescent culture alienation has very important significance for the individual psychological adaptation and adjustment.

The present study found that Chinese national identity and national identity of minority college students are significantly positive correlation with social support. Chinese identity and the national identity positively affect their social support. Social support and subjective well-being is significantly positive correlation. Social support is the intermediate variable of the national identity and subjective well-being [3].Subjective well-being is an important indicator of mental health. Cultural alienation is a form of psychological alienation, and is also a key indicator of mental health [2]. Xiang Ling and Su Wen [4] believe that Alienation is an integral part of the symptoms of depersonalization which shows an emotion that separate to the society, and also lack of social support and meaningful social connections so that the individual produce the negative emotion of senses which are social isolation, control, non-sense, oppression and restraint, self-alienation and other negative emotions. Therefore, this study holds that social support is an important mediator of national identity and cultural alienation.

In the study of alienation and family relations, some researchers such as Rao Yanting found that family cohesion and mother's emotional expression may be the most important factors of College Students' Alienation [5]. Some researchers such as Tang Yizheng found that the high alienation adolescents whose family function usually exists problems which family members have poor intimacy and adaptability [6].

$\mathrm{Xu}$ Fuzhen's research holds that family function can predict the alienation of adolescents. Adolescents with lower family functioning health had higher alienation [7].Wang Mingzhong argue that parental emotional warmth has an impact on adolescent loneliness [8].Social psychology researchers reveal that the national identity makes the individuals within the same nation that show the phenomenon of internal group preference, so the national identity become the spiritual link to maintain the emotional connection between national members. This research believe that the degree of intimacy between family members is another mediator variable of national identity and cultural alienation.

There are two or more intermediate variables between independent variables and dependent variables, which is called multiple mediation model [9].Based on the above analysis, the research hypothesis, family intimacy and social support may play multiple mediating effects on the relationship between national identity and cultural alienation, and a plurality of intermediary variables showed a sequence of characters, forming a chain of multiple mediation model, as shown in Figure I. This study assumes four relationship paths. Firstly, national identity has a direct influence on cultural alienation. Secondly, national identity influences cultural alienation 
through family intimacy. Thirdly, national identity affects cultural alienation through social support. Fourthly, national identity influences social support through family intimacy, and then affects cultural alienation.

On the basis of the previous literature, this study further explores the internal mechanism of national identity and cultural alienation, to discuss how national identity influence on cultural alienation and how better to deal with cultural alienation. It plays a very important role in improving the national identity and cultural adaptation, and improving the level of mental health education.

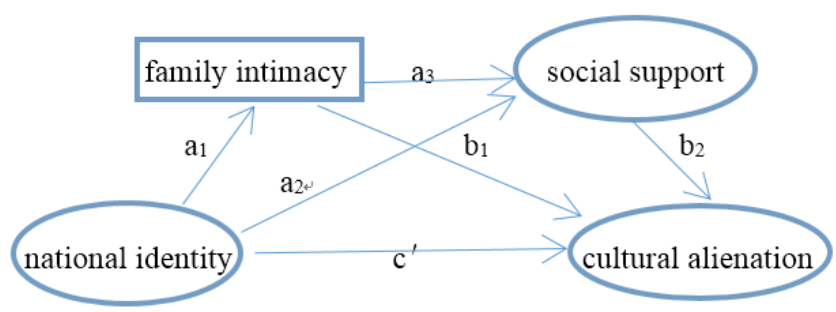

FIGURE I. THE MULTIPLE MEDIATION HYPOTHETICAL MODEL OF NATIONAL IDENTITY, FAMILY INTIMACY, SOCIAL SUPPORT AND CULTURAL ALIENATION

\section{RESEARCH MethodS}

\section{A. Research Objects}

We selected the $\mathrm{Li}$ students who influence the native culture and mainstream culture at the same time as research objects. We choose students who from junior 1 to senior 2 of Le Dong Siyuan experimental school which located in Hainan mid-west and have Han community environment, and also choose Wu Zhishan campus of Hainan Tropical Ocean University's Li university students, taking class as a unit. We recycle 1008 effective questionnaires. The students, 12 to 23 years old, average 17 years old $(S D=2.65)$, are tested. There are 296 boys and 697 girls, lacking of 15 students. Junior 1 have 106 students, junior 2 have 129 students, junior 3 have 133 students, senior 1 have 237 students, senior2 have 82 students, freshman have 143 students, sophomore have 134 students, Junior students have 134, lacking of 4 students.

\section{B. Research Instruments}

\section{1) National identity questionnaires}

We use the national identity questionnaires of Shi Huiying and Zhang Qinglin [10]. There are thirty questions in this survey. Adapting Likert's five points to keep the score, from the "very inconsistent" to "very well" were given 1 to 5 points of the assessment. This questionnaire includes ethnic identity, Chinese national identity questionnaire and test questions. The ethnic identity questionnaire includes three dimensions: social identity, identity and cultural identity. Chinese national identity questionnaire includes two dimensions: Chinese national identity, Chinese national social and culture identity. This questionnaire has 4 reverse scoring questions. It shows that it have higher average score of each questionnaire, will have higher national identity. In this study, Cronbach's Alpha coefficient of ethnic identity and Chinese national identity are 0.730 and 0. 654. Total questionnaires Cronbach's Alpha coefficient is 0.811 .

\section{2) Cultural alienation questionnaire}

This scale was compiled by Liu Xi and Yang Dong in 2005[11]. The scale consists of 37 items, including four dimensions which are cultural isolation, cultural separation, disharmony and sense of control. We use 5 review methods, that is, "do not meet" to "fully consistent" were recorded from 1 to 5 points. After the reverse score, we calculate average score and total score of each dimension, if have higher score, will have higher degree. In this paper, Cronbach's Alpha coefficient of the whole questionnaire is 0.839 .

\section{3) Social support scale}

We used the adolescents social support scale which were made by Ye Yuemei and Dai Xiaoyang[12]. It Includes subjective support, objective support and support utilization dimension, we use 5 points, from the "non-conformity" to "coincidence" in the order of 1 to 5 points. Cronbach's Alpha coefficient of the whole questionnaire is 0.894.

\section{4) Family intimacy and acculturation scale}

We use the family intimacy and acculturation scale of Olson (FACES II)[12]. It reflects the actual feeling of their own family's situation. There are 30 projects in this scale, five grades, from "not" to "regular" respectively from 1 to 5 points. Cronbach's Alpha coefficients of the intimacy and acculturation scale are 0.785 and 0.797 . The whole questionnaires Cronbach's Alpha coefficient is 0. 888.

\section{Data Analysis}

We used SPSS20.0 and MPLUS to analyze. We used the percentile Bootstrap method and test the significance of the mediating effect.

\section{RESEARCH RESULTS}

\section{A. Descriptive Statistics of National Identity, Cultural Alienation, Family Intimacy and Social Support of Li Minority Adolescents}

Teenagers in national identity $(M=3.97)$, Chinese national identity $(M=4.04)$ and the ethnic identity $(M=3.90)$ scores were higher than 3 points, showed that teenagers have higher national identity, the identity of the Chinese nation can identify with their ethnic identities. Based on the paired sample $\mathrm{T}$ test of the two levels of Chinese national identity and ethnic identity, the difference between the ethnic identity and Chinese identity is significant ( $T=--10.749, P<0.001)$, Chinese national identity is significantly higher than the ethnic identity. This reflects the integration of the Li minority youth and the Han nationality, and the national identity of the Li ethnic group is a harmonious unity of the Chinese nation identity and the ethnic identity.

Teenagers in culture alienation $(M=2.29)$ and its four dimensions of cultural isolation $(M=2.11)$, culture separation $(M=2.36)$, sense of disharmony $(M=2.13)$, sense of control $(M=2.72)$ scores were less than 3 points. This result shows that the cultural alienation of the Li nationality adolescents is low.

The total scores of social support scale $(M=3.85)$, subjective support $(M=3.82)$, objective support $(M=3.96)$ and support utilization $(M=3.75)$ subscale scores were higher than 3 points. This result reflects the general situation of the social 
support and subjective support, and the objective support and support utilization are better.

The actual family intimacy $(M=67.74)$ and actual family adaptability $(M=45.72)$ of $\mathrm{Li}$ adolescents, according to Olson's family circumpolar model [12], indicate that the family belongs to the equilibrium type.

\section{B. The Correlation of National Identity, Social Support, Family Intimacy and Cultural Alienation}

It shows in Table I, ethnic identity, Chinese national identity, national identity, social support and family intimacy are positive correlation, and cultural alienation are negative correlation.

TABLE I. DESCRIPTIVE STATISTICS AND CORRELATION ANALYSIS OF VARIABLES(N-1008)

\begin{tabular}{|l|l|l|l|l|l|l|l|l|}
\hline variables & $M$ & $S D$ & 1 & 2 & 3 & 4 & 5 & 6 \\
\hline $\begin{array}{l}\text { 1.ethnic } \\
\text { identity }\end{array}$ & 3.90 & 0.52 & - & & & & & \\
\hline $\begin{array}{l}\text { 2.Chinese } \\
\text { national } \\
\text { identity }\end{array}$ & 4.04 & 0.47 & $.61^{* *}$ & - & & & & \\
\hline $\begin{array}{l}\text { 3.national } \\
\text { identity }\end{array}$ & 3.97 & 0.45 & $.91^{* *}$ & $.89^{* *}$ & - & & & \\
\hline $\begin{array}{l}\text { 4.family } \\
\text { intimacy }\end{array}$ & 67.74 & 9.31 & $.24^{* *}$ & $.22^{* *}$ & $.25^{* *}$ & - & & \\
\hline $\begin{array}{l}\text { 5.social } \\
\text { support }\end{array}$ & 3.85 & 0.63 & $.27^{* *}$ & $.30^{* *}$ & $.31^{* *}$ & $.43^{* *}$ & - & \\
\hline $\begin{array}{l}\text { 6.cultural } \\
\text { alienation }\end{array}$ & 2.29 & 0.43 & $-.26^{* *}$ & $-.32^{* *}$ & $-.32^{* *}$ & $-.23^{* *}$ & $-.23^{* *}$ & - \\
\hline
\end{tabular}

C. The Influence Mechanism of Li Adolescent National Identity to Cultural Alienation

1) The influence of $\mathrm{Li}$ adolescent national identity to cultural alienation

We use cultural alienation as the dependent variable, and use $\mathrm{Li}$ adolescent national identity, ethnic identity and Chinese national identity as predictive variables. We adapt the method of forced into regression to analyze. The results show that the regressive standard of $\mathrm{Li}$ adolescent national identity, ethnic identity and Chinese national identity are obvious, and it can negatively predict the cultural alienation. It shows in Table II.

TABLE II. THE REGRESSIVE STANDARD OF LI ADOLESCENT NATIONAL IDENTITY ANALYZE TO CULTURAL ALIENATION

\begin{tabular}{|c|c|c|c|c|c|c|}
\hline $\begin{array}{c}\text { Dependent } \\
\text { variable }\end{array}$ & $\begin{array}{c}\text { Predict } \\
\text { variable }\end{array}$ & $R^{2}$ & $F$ & Beta & $t$ & $p$ \\
\hline $\begin{array}{c}\text { Cultural } \\
\text { alienation }\end{array}$ & national identity & 0.104 & $117.173^{* * *}$ & -0.309 & -10.825 & 0.000 \\
\hline $\begin{array}{c}\text { Cultural } \\
\text { alienation }\end{array}$ & ethnic identity & 0.069 & $74.677^{* * *}$ & 0.263 & 8.642 & 0.000 \\
\hline $\begin{array}{c}\text { Cultural } \\
\text { alienation }\end{array}$ & $\begin{array}{c}\text { ethnic identity } \\
\text { Chinese national } \\
\text { identity }\end{array}$ & 0.109 & $61.775^{* * *}$ & 0.107 & 2.829 & 0.005 \\
\hline
\end{tabular}

2) Multiple mediating effects of family intimacy and social support

Wen Zhonglin, Liu Yunhong and Hou Jietai argue that the mediation researches can explain the mechanism of the relationship between independent variables and dependent variables [13]. The relationship of national identity and cultural alienation is close. How the mediating effects of national identity through family intimacy and social support to influence the cultural alienation, and it form multiple intermediary inspection through to establish structural equation model. It can analyze the specified path of mediating effects, the total mediating effect and mediating effect comparison [14]. According to Fang Jie and Wen Zhonglin who put forward the multiple mediating effects of SEM process, to analyze it.

Firstly, the multiple mediation model is determined, and the fitting degree of the model is test. We can get the results of model fitting by MPLUS software. It shows as follow: $\chi^{2}=479$. 11 , freedom degree $d f=6, \chi^{2} / d f=4$. 88, $C F I=1.00, T L I=1$. $00, R M S E A=.00$. The model fitting degree is very good.

Then, setting the auxiliary variables as $a_{1} a_{3} b_{2}-a_{1} b_{1}$, $a_{1} a_{3} b_{2}-a_{2} b_{2}, a_{1} b_{1}-a_{2} b_{2}$.

Finally, we used the method of Bootstrap to analyze the multiple mediating, and get the results of mediating effects showing in Table III.

TABLE III. THE SEM RESULTS OF MULTIPLE MEDIATING OF NATIONAL IDENTITY, FAMILY INTIMACY, SOCIAL SUPPORT AND CULTURAL ALIENATION

\begin{tabular}{|c|c|c|cc|}
\hline & \multirow{2}{*}{$\begin{array}{c}\text { Standardized } \\
\text { indirect effects } \\
\text { estimation }\end{array}$} & $\begin{array}{c}\text { Average } \\
\text { indirect } \\
\text { effects }\end{array}$ & \multicolumn{2}{|c|}{$\begin{array}{c}\text { 95\%confidence } \\
\text { interval }\end{array}$} \\
\cline { 4 - 5 } & upper & lower \\
\hline $\begin{array}{c}\text { National identity - } \\
\text { family intimacy }- \\
\text { cultural alienation }\end{array}$ & $\begin{array}{c}5.31 *(-0.01) \\
=-0.05\end{array}$ & -0.03 & -0.05 & -0.02 \\
\hline $\begin{array}{c}\text { National identity- } \\
\text { social support - } \\
\text { cultural alienation }\end{array}$ & $\begin{array}{c}0.31 *(-0.07) \\
=-0.02\end{array}$ & -0.02 & -0.04 & -0.01 \\
\hline $\begin{array}{c}\text { National identity- } \\
\text { family intimacy- } \\
\text { social support- } \\
\text { cultural alienation }\end{array}$ & $\begin{array}{c}5.31 * 0.03 *(- \\
0.07)=-0.01\end{array}$ & 0.00 & -0.02 & -0.003 \\
\hline
\end{tabular}

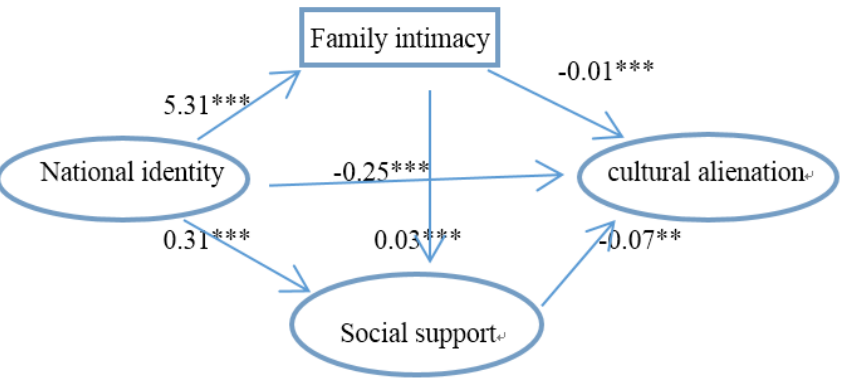

FIGURE II. THE MULTIPLE MEDIATING EFFECTS OF NATIONAL IDENTITY, FAMILY INTIMACY, SOCIAL SUPPORT AND CULTURAL ALIENATION

\section{CONCLUSION}

According to the SEM results of multiple mediation shows in Table III and Figure II, we know the results as following.

- Firstly, Li adolescents national identity has negative predictive effect on culture alienation, the total effect $c$ was -0.261 , the direct effect was significant $\left(c^{\prime}\right.$ $=-0.208, \quad p<0.001)$ the total indirect effect was significant too $\left(c-c^{\prime}=-0.053, p<0.001\right)$.

- Secondly, $\mathrm{Li}$ adolescents national identity can indirectly influence the cultural alienation $\left(a_{1} b_{1}\right.$ $=-0.032, \quad p<0.01$ ) by family intimacy, but also indirectly influence cultural alienation $\left(a_{2} b_{2}=-0.021\right.$, $p<0.05$ ) by social support; Family intimacy and social support play a parallel multiple mediation roles 
between Li adolescents’ national identity and cultural alienation.

- Thirdly, Li adolescents national identity not only directly influence cultural alienation, but also influence family intimacy by social support, and further influence the cultural alienation $\left(a_{1} a_{3} b_{2}=-0.009\right.$, $p<0.05$ ), forming a chain of multiple mediation. According to table III, we know that the confidence intervals of each path are not included 0 , which verified the mediating effect of family intimacy and social support in national identity and cultural alienation.

- Fourthly, we know that $\mathrm{Li}$ adolescents' national identity influence culture alienation, there are $12.3 \%$ effective by family intimacy. There are $8 \%$ effective by social support. There is no significant difference between the role of family intimacy, national identity and cultural alienation and the role of social support, national identity and cultural alienation. They have similar important roles. However, the multiple mediating effects of social support and family intimacy were obvious higher than that of family intimacy and social support.

To conclusion, this research argues that the two major factors of family and society are influence of the important mediating variables between national identity and cultural alienation. In order to avoid producing the sense of emptiness, loneliness, incapable which caused by the cultural difference, when minority students contact with the mainstream cultural, Family members should pay more attention to the growth of minority adolescents, focusing on family member emotional connection. Meanwhile, we should make the minority adolescents to feel the social support from friends, classmates and relatives. We also should create the environment about equal respect, relaxed and harmonious, mutual growth. It will promote positive and health national identity senses, cultural adaptation and mental health of minority students. It will maintain the harmony of multinational country.

\section{ACKNOWLEDGEMENTS}

Key Research Project for Humanities and Social Sciences of Ministry of Education (14JJD880009); Hainan Provincial Philosophy and Social Science Project (HNSK(YB)15-129)

\section{REFERENCES}

[1] Yang Dong, Jin Zhao, Li Ying. Researches on Culture Alienation of Ethnic Minorities in Han Nationality. Sociological Studies, vol.3, pp.187-210, 2009.

[2] Jiang YongZhi, Bai XiaoLi. Research on Cultural Alienation and Characteristics of Mongolian College Students Under the Perspective of Harmonious Society. Research on Higher Education of Nationalities, vol.2, pp.1-6, 2014.

[3] Yang Bao-Shan. Correlation Researches on the Chinese identity of minority college students, social support and subjective well-being .YunNan Normal University, 2014.

[4] Xiang ling, Su Wen. Research progress of adolescent alienation. China Electric Power Education, pp.158- 160,2011.

[5] Rao YanTing, Zhang HongXia, Li XiaoMing. Impact of the Family Factors on College Students' Depression and Alienation. Psychological Development and Education, pp.70-76,2004.
[6] Tang YiHui, Huang Hai, Lei LiangXin. Relationship among the Family Functioning and Personality and Alienation of Adolescents. Chinese Journal of Clinical Psychology, vol.12, pp.158-160, 2004.

[7] XU FuZhen, ZHANG Wen-Xin, ZHANG Ling-Ling. Effect of Family Functioning on Adolescents' Alienation: Moderated Mediating Effect. Acta Psychologica Sinica, vol.41, pp.1165-1174,2009.

[8] Wang Mingzhong Zhou Zongkui. Influence of Parental Warmth on Adolescents' Loneliness: Analysis of Multiple Mediation Effect. Psychological Exploration, vol.35, pp.41-44,2015.

[9] Liu Shishun, Ling Wenquan. Multiple Mediation Models and Their Applications. Psychological Science, vol,32, pp.433-435,2009.

[10] Shi Huiying, Zhang Qinglin, Zhang Jinmei. Ethnic identity and behavior adaptation of ethnic minorities in Southwest China. Chongqing: Chongqing University press, pp. 103-104, 2012.

[11] Liu Xi, Yang Dong. Sense of Cultural Alienation on Minority Students Living in Han Nationality District-The Theoretical Hypothesis and Questionnaire Designing. Chinese Journal of Clinical Psychology, vol.13, pp. 141-146,2005.

[12] Dai Xiaoyang. Handbook of psychological assessment scale. Beijing: People's Medical Publishing House, pp. 90,163, 2012.

[13] Web Zhonglin, Liu Hongyun, Hou Jietai. Analyses of Moderating and Mediating Effects .Education Science Press, pp.78-80, 2012.

[14] Fang Jie, Wen Zhonglin, Zhang Minqiang ,Sun Peizhen. The Analyses of Multiple Mediation Effects Based on Structural Equation Modeling .Journal of Psychological Science, vol.37, pp. 735-741,2014. 